\title{
Low Risk of Clostridium difficile Infections in Hospitalized Patients with Inflammatory Bowel Disease in a German Tertiary Referral Center
}

\author{
Claudia Ott $^{a} \quad$ Christiane Girlich $^{a} \quad$ Frank Klebl $^{a} \quad$ Annelie Plentz $^{c} \quad$ Igors lesalnieks ${ }^{b}$ \\ Jürgen Schölmerich ${ }^{a}$ Florian Obermeier ${ }^{\mathrm{a}}$
}

Departments of a Internal Medicine I and b Surgery, and c Institute for Microbiology and Hygiene,

University of Regensburg, Regensburg, Germany

\section{Key Words}

Clostridium difficile infection - Inflammatory bowel disease •

Crohn's disease $\cdot$ Ulcerative colitis $\cdot$ Immunosuppressive therapy

\begin{abstract}
Introduction: Many reports, mainly from the US and Canada but also a recent report from a center in Europe, have documented the increasing impact of Clostridium difficile infections in patients with inflammatory bowel disease (IBD) during the last years. To determine the prevalence of $C$. difficile infections in hospitalized IBD patients in a tertiary referral center in Germany, we conducted this retrospective analysis. Methods: Data of all IBD in-patients treated due to an acute flare of their IBD at the Department of Internal Medicine I of the University of Regensburg between January 1, 2001, and June 30, 2008, were analyzed. In patients with a concomitant diagnosis of $C$. difficile infection, further variables such as IBD-related treatment at the time of infection or outcome were examined. Results: In total, 995 in-patients with IBD were treated in this hospital $[638$ patients with Crohn's disease (CD), 357 with ulcerative colitis (UC)] during the study period. Of these, 279 patients with CD and 242 patients with UC were admitted with an acute flare and suffering from diarrhea and abdominal pain. Only 10 of those were diagnosed
\end{abstract}

\section{KARGER}

Fax +4161306 1234 E-Mail karger@karger.ch www.karger.com

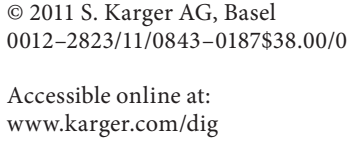

as having a concomitant infection with $C$. difficile. Six patients were female and the median age was 49 years (range: 15-80). Six patients with C. difficile infections suffered from $\mathrm{UC}$ and 4 patients from $C D$, all with previous colonic involvement. Eight patients used immunosuppressive therapies; only 2 patients were treated with antibiotics before infection. Conclusion: In contrast to recent reports from other countries, only a low percentage of hospitalized patients with acute flares of their IBD were identified as having an underlying $C$. difficile infection in this German tertiary referral center. However, in IBD patients with an acute flare, a concomitant $C$. difficile infection should be excluded, especially in patients with immunosuppressive treatment and colonic involvement of their disease. Further research is needed to evaluate if regions with different risks of $C$. difficile infections exist and to find out more about potential reasons for this observation.

Copyright $\odot 2011$ S. Karger AG, Basel

\section{Introduction}

A large number of reports from many different regions have documented the rising incidence of Clostridium difficile infections during the last decade $[1,2]$. Elderly patients are particularly susceptible to infections; addi- 
tionally, factors like recent use of antibiotics and immunosuppressive drugs and systemic comorbidities are suggested to increase the risk of C. difficile infection [2].

After regional outbreaks of $C$. difficile in the US, Canada and subsequently in parts of Europe, a hypervirulent epidemic strain of $C$. difficile (North American pulsedfield type 1, PCR ribotype 027) resistant to fluroquinolone attracted a great deal of attention [3-5].

As patients with inflammatory bowel disease (IBD) comprising Crohn's disease (CD) and ulcerative colitis (UC) - frequently present with diarrhea and abdominal pain, differentiation between an acute flare and enteric infection seems to be necessary in this setting. This is even more so since several studies, mainly from the US and Canada, have documented a dramatic rise of $C$. difficile infections in patients with IBD, both in studies from tertiary referral centers and in national surveys [6-10]. More recently, an increasing incidence in IBD patients has also been identified in Greece [11] and Belgium [12], as well as a high prevalence of $C$. difficile infection in Italian pediatric IBD patients [13]

However, data on the impact of $C$. difficile infections in adult IBD patients from other centers in Europe are missing. Therefore, the purpose of this retrospective study was to assess the prevalence of $C$. difficile infections in patients with IBD in a tertiary center in Germany.

\section{Study Cohort}

All in-patients treated for an acute flare of their IBD at the Department of Internal Medicine I of the University of Regensburg between January 1, 2001, and June 30, 2008, were included in this retrospective analysis. Every single admission of a patient was evaluated separately if the patient was admitted to our department more than once. Patients hospitalized only due to disease complications (e.g. fistulas or extraintestinal manifestations), but not suffering from diarrhea, were excluded from this study.

The University of Regensburg is a tertiary referral center which treated 29,162 in-patients in 2007, 3,690 of whom were treated at the Department of Internal Medicine I. IBD patients are referred to this institution from primary care physicians as well as from secondary and primary centers.

The diagnosis of CD, UC or indeterminate colitis was based on endoscopic, histological and radiological findings.

For all patients included in the study, computer-based discharge registries were searched using text searches for 'Clostridium difficile', 'C. difficile' or 'C. diff.' to identify patients with this concomitant diagnosis. Patient records were checked to identify every patient which was tested for $C$. difficile infection during the relevant hospitalization. The diagnosis of $C$. difficile infection was made by stool toxin analysis (ELISA stool toxin A and B) and/ or histological evidence with classic pseudomembrane formations.
In patients with a concomitant diagnosis of $C$. difficile infection, further demographic data such as age, time since first diagnosis of IBD, clinical symptoms, IBD-related treatment at time of infection, nosocomial infection, season at time of infection, treatment for $C$. difficile infection and outcome were collected.

Statistical analyses were performed using SPSS software (16.0, Chicago, Ill., USA).

\section{Results}

\section{Basic Characteristics}

During the study period between January 1, 2001, and June 30, 2008, 995 in-patients with IBD were treated in this hospital (638 patients with CD, 357 with UC). In 279 patients with $\mathrm{CD}$ and 242 patients with $\mathrm{UC}$, an acute flare with typical symptoms of diarrhea and abdominal pain was the reason for hospital admission. Other reasons for admission were fistulas or extraintestinal manifestations. Patients treated due to disease complications were not included in this analysis.

In all IBD patients with an acute flare, 438 stool tests on pathogenic intestinal bacteria were performed (82.5\%). 248 patients were tested particularly with regard to $C$. difficile by stool toxin analysis ( $47.6 \%$ of all patients), with 120 patients diagnosed as having $\mathrm{CD}$, and 128 patients diagnosed with UC. The number of tests per year in IBD patients with a flare of their disease is presented in table 1.

In total, 3,267 samples from all the patients treated at the Department of Internal Medicine I - including nonIBD patients - were tested for $C$. difficile during the study period at the Institute for Microbiology and Hygiene. In this entire population, an increase of $C$. difficile infections was observed, peaking in 2005 with positive test results in $12.7 \%$ of the patients. Between 2001 and 2004, 93 of 1,661 tests on C. difficile infections were positive, and between 2005 and 2008, 166 of 1,606 tests showed positive results ( $\mathrm{p}<0.0001$, Fisher's exact test).

\section{IBD Patients with C. difficile Infection}

Only 10 of all the IBD patients with symptoms of an acute flare with diarrhea were diagnosed as having a concomitant infection with C. difficile (3.9\% of all tested IBD patients). In 9 of the 10 patients, the diagnosis of $C$. difficile infection was confirmed by stool toxin analysis; in 1 patient the diagnosis was made endoscopically and histologically despite negative stool toxin analysis.

Of the 10 patients, 6 were female and the median age was 49 years (range: $15-80$ ). Six patients with $C$. difficile infections had UC ( $2.7 \%$ of all tested patients with UC). Of the remaining $4 \mathrm{CD}$ patients ( $4 \%$ of all tested patients 


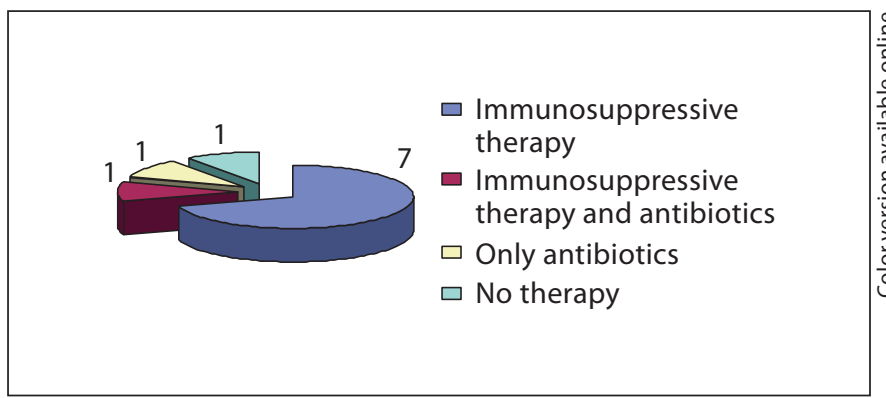

Fig. 1. Therapy at time of infection.

with CD), 1 patient showed a superinfection with $C$. difficile at the time of first diagnosis of IBD. In 2 patients, both of whom had UC, the time of first diagnosis of IBD was less than 1 year before infection with C. difficile. In addition, patients with a history of IBD stretching back more than 10 years were affected. Interestingly, in all patients with $\mathrm{CD}$, involvement of the colon was documented (table 2).

\section{Medication at Time of Infection}

Eight patients with concomitant C. difficile infection had immunosuppressive therapies such as corticosteroids (6 patients) or azathioprine (2 patients) at the time of infection. Only 2 patients were treated with antibiotics before $C$. difficile infection was diagnosed, and one of these patients was simultaneously treated with azathioprine (fig. 1). No patient was on anti-TNF therapy. There was no seasonal variation of C. difficile infections (fig. 2).

One infection was found each during the years 20012004 and 2006-2007 and 2 infections each during 2005 and 2008. Comparing the first 4 years (2001-2004) to the next 3.5 years (2005-2008) of the observation period, no statistically significant difference between the two periods was seen ( $\mathrm{p}=0.21$, Fisher's exact test).

\section{Outcome}

All patients were successfully treated with metronidazole, except for the patient with concomitant $C$. difficile infection at the time of first diagnosis of $\mathrm{CD}$. In this patient, a total proctocolectomy became necessary due to toxic megacolon. All other patients showed remission of symptoms during antibiotic therapy. Additionally, in 7 patients, stool toxin was negative after withdrawal of metronidazole. None of the patients revealed a recurrence of episodes of $C$. difficile infections after primary treatment.

C. difficile Infections in IBD Patients in Germany

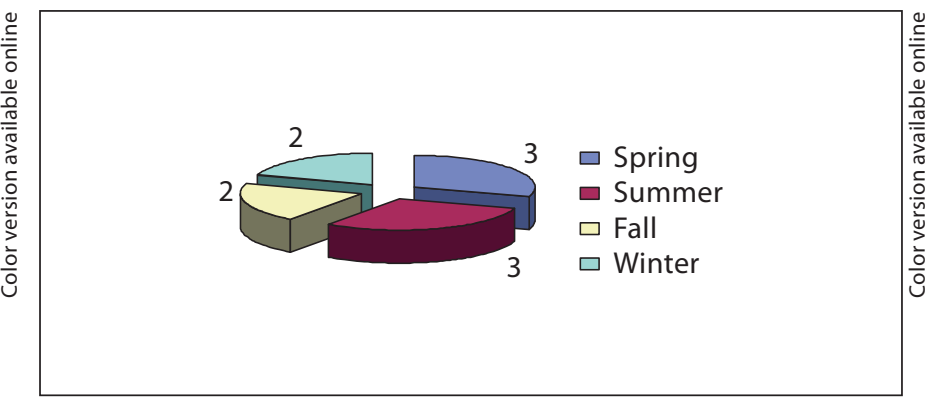

Fig. 2. Season at time of infection.

Table 1. Tested patients with flare-ups per year

\begin{tabular}{llll}
\hline Year & $\begin{array}{l}\text { Number } \\
\text { of flare-ups }\end{array}$ & $\begin{array}{l}\text { Number of tests } \\
\text { on C. difficile }\end{array}$ & $\begin{array}{l}\text { Patients with } \\
\text { flare tested, \% }\end{array}$ \\
\hline 2001 & 96 & 43 & 44.8 \\
2002 & 66 & 34 & 51.5 \\
2003 & 79 & 31 & 39.2 \\
2004 & 73 & 28 & 38.4 \\
2005 & 66 & 26 & 39.4 \\
2006 & 53 & 27 & 50.9 \\
2007 & 59 & 36 & 61.0 \\
2008 (until June 30) & 29 & 23 & 79.3 \\
\hline
\end{tabular}

\section{Discussion}

In this retrospective observational study over a 7-year period, we found only a few hospitalized patients with IBD and concomitant $C$. difficile infection in this tertiary referral center. These results are even more interesting since the incidence of $C$. difficile infections in the total patient population in this department showed a significant increase during the study period, which is similar to results from other centers. Our observation with regard to IBD patients therefore stands in contrast to several reports, mainly from North America.

An alarming rise in the incidence and prevalence of C. difficile infections in IBD patients has been described both in studies from single tertiary specialty centers and reports using nationwide databases [6-10]. Worse outcomes and higher mortality were also seen in patients with $C$. difficile infections and underlying IBD with a rising case fatality during the later years [7,9]. In our series, we could not find an increase of $C$. difficile infections in our patients during the observation time in spite of rising awareness of possible infections in the later years. This is

Digestion 2011;84:187-192 
Table 2. Characteristics of all patients with C. difficile infection and IBD

\begin{tabular}{|c|c|c|c|c|c|c|c|}
\hline Gender & Kind of IBD & $\begin{array}{l}\text { Age } \\
\text { years }\end{array}$ & $\begin{array}{l}\text { Developed } \\
\text { C. difficile during } \\
\text { hospital stay }\end{array}$ & Symptoms & Therapy & $\begin{array}{l}\text { Time since first } \\
\text { diagnosis of IBD }\end{array}$ & $\begin{array}{l}\text { Colonic } \\
\text { involve- } \\
\text { ment }\end{array}$ \\
\hline Female & UC (pancolitis) & 51.0 & no & watery diarrhea & metronidazole & $<1$ year & yes \\
\hline Male & $\mathrm{CD}$ & 47.0 & yes & toxic megacolon & surgery & at first diagnosis & yes \\
\hline Female & UC (left-sided) & 30.0 & no & $\begin{array}{l}\text { watery diarrhea, } \\
\text { abdominal pain }\end{array}$ & metronidazole & $>10$ years & yes \\
\hline Female & UC (pancolitis) & 15.0 & no & watery diarrhea & metronidazole & $<1$ year & yes \\
\hline Male & UC (pancolitis) & 52.0 & yes & fever & metronidazole & $>10$ years & yes \\
\hline Female & $\mathrm{CD}$ & 47.0 & no & watery diarrhea & metronidazole & $>10$ years & yes \\
\hline Male & UC (proctitis) & 60.0 & no & watery diarrhea & metronidazole & $1-3$ years & yes \\
\hline Female & UC (pancolitis) & 80.0 & yes & watery diarrhea & metronidazole & $5-10$ years & yes \\
\hline Female & $\mathrm{CD}$ & 72.0 & no & $\begin{array}{l}\text { watery diarrhea, } \\
\text { abdominal pain, fever }\end{array}$ & metronidazole & $3-5$ years & yes \\
\hline Male & $\mathrm{CD}$ & 28.0 & no & $\begin{array}{l}\text { watery diarrhea, } \\
\text { abdominal pain }\end{array}$ & metronidazole & $>10$ years & yes \\
\hline
\end{tabular}

${ }^{1}$ Defined as primary negative test result with a subsequent positive result during the hospital stay.

Table 3. Summary of the existing literature

\begin{tabular}{|c|c|c|c|c|}
\hline First author & Patient population & Testing methods & $\begin{array}{l}\text { Incidence or prevalence of } \\
\text { C. difficile infection }\end{array}$ & Trends of C. difficile infections \\
\hline Rodemann [6] & IBD vs. non-IBD & stool toxin analysis & doubled in CD, tripled in UC & increasing \\
\hline Ananthakrishnan [7] & IBD vs. non-IBD & n.a. & n.a. & $\begin{array}{l}\text { increasing, IBD associated with } \\
\text { worse outcome }\end{array}$ \\
\hline Nguyen [8] & IBD vs. non-IBD & n.a. & doubled in UC & $\begin{array}{l}\text { increasing, IBD associated with } \\
\text { higher mortality in UC }\end{array}$ \\
\hline Ricciardi [9] & $\begin{array}{l}\text { IBD vs. non-IBD, } \\
\text { national survey }\end{array}$ & n.a. & $\begin{array}{l}\text { rising in UC and CD with } \\
\text { colonic involvement }\end{array}$ & UC with increasing case fatality \\
\hline Issa [10] & IBD, referral center & stool toxin analysis & doubled in IBD & $\begin{array}{l}\text { use of immunosuppressive } \\
\text { drugs and colonic involvement } \\
\text { as risk factors }\end{array}$ \\
\hline Bossuyt [12] & IBD vs. non-IBD & stool toxin analysis & 3.75-fold increase & $\begin{array}{l}\text { use of immunosuppressive } \\
\text { drugs not influencing the risk }\end{array}$ \\
\hline Pascarella [13] & $\begin{array}{l}\text { pediatric IBD vs. } \\
\text { non-IBD, single-center }\end{array}$ & stool toxin analysis & $\begin{array}{l}\text { higher prevalence in IBD vs. } \\
\text { non-IBD }\end{array}$ & \\
\hline Mylonaki [15] & IBD, acute flare & stool toxin analysis & $5.5 \%$ over 5 -year period & \\
\hline Ott (this study) & IBD, acute flare & $\begin{array}{l}\text { stool toxin analysis, } \\
\text { flexible sigmoidoscopy }\end{array}$ & $3.9 \%$ over 7.5 -year period & \\
\hline
\end{tabular}

n.a. = Not applicable. 
confirmed by our data showing an increasing percentage of IBD patients with flare being tested, especially since 2006. In addition, we could not find a seasonal variation of $C$. difficile infection, although it has been described in previous studies with a lower risk of infection in summer months $[8,14]$. A summary of the existing literature on C. difficile infections in IBD patients is given in table 3.

Mylonaki et al. [15] found 5.5\% of the relapses in IBD patients to be associated with $C$. difficile infections in their case series from Great Britain, which is comparable to the results obtained in our retrospective study (3.9\% of all tested IBD patients with diarrhea). In contrast to their study, where $60 \%$ of the patients with an acute flare were tested for C. difficile toxin, we tested for C. difficile infection in only $48 \%$ of the patients with a diarrheal flare. Not testing all the patients with diarrhea has to be considered the main limitation of our study, despite the increasing numbers of patients with acute flares being tested during the later years.

In this context, possible underdiagnosing of $C$. difficile infection might be caused by the application of antibiotic therapy without prior testing. In our series, a total number of 92 of 521 flares (17.6\%) were treated with antibiotic therapy, although no test on $C$. difficile was performed.

Another limitation was the toxin-based ELISA used for testing in our study, which is known to be less sensitive (70-90\%) than cytotoxicity tests. Repeated testing has been shown to increase the diagnostic yield to up to $92-95 \%[1,16]$. Nevertheless, there are some controversies on repeated testing for $C$. difficile infection. In their study, Nemat et al. [17] showed a low value of repeated tests, and repeated testing has been suggested to result in false-positive tests [18]. Therefore, a clear guideline recommending the optimal number of tests still does not exist. At our department, initially one test is performed in IBD patients with diarrhea. If the patient does not respond to anti-inflammatory treatment, a second stool test is ordered as well as endoscopic investigations, which led to the diagnosis in one of our patients despite negative stool toxin analysis.

The varying incidence of $C$. difficile infections in different countries might partly be explained by differences of the examined patient populations. For example, different strategies in the treatment of patients with IBD, e.g. the frequent use of anti-TNF therapies in several countries, might play a role. A previous report identified immunosuppressive therapies as an important predisposing factor for C. difficile infections [19]. This is supported by our results as $80 \%$ of our positive patients received immunosuppressive therapy prior to the diagnosis of $C$. difficile infection. Surprisingly, prior use of antibiotics, which is known as the main cause for $C$. difficile infection in the general population was only found in 2 patients [2]. Although C. difficile infections may not be limited to the colon $[1,20]$, in all of our patients with CD, colonic involvement was seen. Therefore, one may speculate that in addition to UC patients, CD patients with colonic involvement are at a higher risk for $C$. difficile infection. This observation is consistent with results of earlier studies identifying colonic disease as a risk factor for C. difficile infection $[8,9]$.

\section{Conclusion}

In this German tertiary referral center only a low percentage of hospitalized patients with IBD were found to have a concomitant $C$. difficile infection. Therefore, in contrast to reports from North America and Belgium, IBD patients hospitalized due to an acute flare have only a moderate risk for $C$. difficile infection in our region. This observation suggests the possibility that low- and high-risk areas for C. difficile infections might exist. As this is the first study showing possible geographic variation, further research on underlying reasons is needed.

Nevertheless, in clinical practice in all IBD patients with an acute diarrheal flare, a superinfection with $C$. difficile should be excluded. This is of special importance in patients with immunosuppressive treatment and colonic involvement to prevent medical malpractice using detrimental immunosuppressive therapies in C. difficile-infected IBD patients, shorten the time of hospitalization and improve patient outcome.

\section{Acknowledgements}

We thank Barbara Effenberger and Wolfgang Huber for performing database searches.

References

Digestion 2011;84:187-192
1 Issa M, Ananthakrishnan AN, Binion DG: Clostridium difficile and inflammatory bowel disease. Inflamm Bowel Dis 2008; 14:14321442.

2 Gould CV, McDonald LC: Bench-to-bedside review: Clostridium difficile colitis. Crit Care 2008; $12: 203$

-3 Morgan OW, Rodrigues B, Elston T, Verlander NQ, Brown DF, Brazier J, Reacher M: Clinical severity of Clostridium difficile PCR ribotype 027: a case-case study. PLoS ONE 2008;3:e1812. 
4 Borgmann S, Kist M, Jakobiak T, Reil M, Scholz E, von Eichel-Streiber C, Gruber H, Brazier JS, Schulte B: Increased number of Clostridium difficile infections and prevalence of Clostridium difficile PCR ribotype 001 in southern Germany. Euro Surveill 2008;13:pii 19057.

$\checkmark 5$ Kuijper EJ, Barbut F, Brazier JS, et al: Update of Clostridium difficile infection due to PCR ribotype 027 in Europe, 2008. Euro Surveill 2008;13:pii 18942.

6 Rodemann JF, Dubberke ER, Reske KA, Seo da H, Stone CD: Incidence of Clostridium difficile infection in inflammatory bowel disease. Clin Gastroenterol Hepatol 2007;5: 339-344.

7 Ananthakrishnan AN, McGinley EL, Binion DG: Excess hospitalisation burden associated with Clostridium difficile in patients with inflammatory bowel disease. Gut 2008;57: 205-210.

-8 Nguyen GC, Kaplan GG, Harris ML, Brant SR: A national survey of the prevalence and impact of Clostridium difficile infection among hospitalized inflammatory bowel disease patients. Am J Gastroenterol 2008; 103:1443-1450.
Ricciardi R, Ogilvie JW Jr, Roberts PL, Marcello PW, Concannon TW, Baxter NN: Epidemiology of Clostridium difficile colitis in hospitalized patients with inflammatory bowel diseases. Dis Colon Rectum 2009;52: 40-45.

-10 Issa M, Vijayapal A, Graham MB, et al: Impact of Clostridium difficile on inflammatory bowel disease. Clin Gastroenterol Hepatol 2007;5:345-351.

-11 Mantzaris GJ CA, Karakoidas C, Papamichael K, Agalos G, Smyrnidis A, Kanellopoulos N, Raptis N, Panaiara O: Ulcerative colitis and Clostridium difficile infection: a changing field. Gut 2008;57:205-210.

12 Bossuyt P, Verhaegen J, Van Assche G, Rutgeerts P, Vermeire S: Increasing incidence of Clostridium difficile-associated diarrhea in inflammatory bowel disease. J Crohns Coli tis 2009;3:4-7.

13 Pascarella F, Martinelli M, Miele E, Del Pezzo M, Roscetto E, Staiano A: Impact of Clostridium difficile infection on pediatric inflammatory bowel disease. J Pediatr 2009 154:854-858.

14 Archibald LK, Banerjee SN, Jarvis WR: Secular trends in hospital-acquired Clostridium difficile disease in the United States, 19872001. J Infect Dis 2004;189:1585-1589.

-15 Mylonaki M, Langmead L, Pantes A, Johnson F, Rampton DS: Enteric infection in relapse of inflammatory bowel disease: importance of microbiological examination of stool. Eur J Gastroenterol Hepatol 2004;16: $775-778$.
16 Navaneethan U, Venkatesh PG, Shen B: Clostridium difficile infection and inflammatory bowel disease: understanding the evolving relationship. World J Gastroenterol 2010;16: 4892-4904.

17 Nemat H, Khan R, Ashraf MS, et al: Diagnostic value of repeated enzyme immunoassays in Clostridium difficile infection. Am J Gastroenterol 2009;104:2035-2041.

-18 Litvin M, Reske KA, Mayfield J, McMullen KM, Georgantopoulos P, Copper S, HoppeBauer JE, Fraser VJ, Warren DK, Dubberke ER: Identification of a pseudo-outbreak of Clostridium difficile infection (CDI) and the effect of repeated testing, sensitivity, and specificity on perceived prevalence of CDI. Infect Control Hosp Epidemiol 2009;30: 1166-1171.

19 Freeman HJ: Recent developments on the role of Clostridium difficile in inflammatory bowel disease. World J Gastroenterol 2008; 14:2794-2796.

20 Wang Y, Shen B: Clostridium difficile-associated diarrhea in Crohn's disease patients with ostomy. Inflamm Bowel Dis 2010;16: $1-2$. 